\title{
Predictive Value of Optimal Morphologic Response to First-Line Chemotherapy in Patients with Colorectal Liver Metastases
}

\author{
Hiroki Yoshita ${ }^{a}$ Ayumu Hosokawa ${ }^{a}$ Akira Ueda $^{a}$ Takayuki Ando ${ }^{a}$ \\ Shinya Kajiura ${ }^{a}$ Hiroshi Kato $^{\text {b }}$ Hideto Kawabe $^{b}$ Gakuto Tomizawa $^{\text {b }}$ \\ Naoki Horikawac Kazuhisa Yabuhitac ${ }^{c}$ Masayuki Note ${ }^{c}$ Toshiro Sugiyama $^{a}$

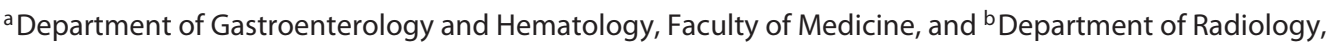 \\ University of Toyama, Toyama, and ' Department of Surgery, Takaoka City Hospital, Takaoka, Japan
}

\author{
Key Words \\ Colorectal cancer · Bevacizumab · Optimal morphologic \\ response $\cdot$ RECIST
}

\begin{abstract}
Background: It has been reported that morphologic response to preoperative chemotherapy is an independent prognostic factor in patients who undergo hepatic resection of colorectal liver metastases (CLM). The aim of this study was to evaluate the predictive value of morphologic response to first-line chemotherapy in patients with CLM. Methods: We assessed 41 patients with CLM who received fluorouracil-based chemotherapy with or without bevacizumab as the first-line chemotherapy between April 2006 and June 2012. Three blinded radiologists evaluated computed tomography images and classified them as optimal, incomplete or no response according to the morphologic criteria. Response to systemic chemotherapy was also evaluated according to Response Evaluation Criteria in Solid Tumors (RECIST). Predictive factors associated with progression-free survival (PFS) were identified in multivariate analysis. Results: Twenty-three patients (56\%) received chemo-
\end{abstract}

\section{KARGER}

E-Mail karger@karger.com www.karger.com/dig therapy with bevacizumab, while 18 patients (44\%) received chemotherapy without bevacizumab. Optimal morphologic response was observed in 11 patients (48\%) treated with bevacizumab and in 5 patients (28\%) treated without bevacizumab ( $p=0.19)$. Eight patients $(20 \%)$ underwent hepatic resection after chemotherapy. The median follow-up period was 31.3 months. The median PFS was 13.3 months for patients with optical morphologic response and 8.7 months in those with incomplete/no morphologic response ( $p=$ 0.0026). On multivariate analysis, performance status and morphologic response were significant independent predictors of PFS. Conclusion: Optimal morphologic response was significantly associated with PFS in patients with CLM who were treated with fluorouracil-based chemotherapy as the first-line chemotherapy.

(c) 2014 S. Karger AG, Basel

\section{Introduction}

In patients with metastatic colorectal cancer (mCRC), fluorouracil-based chemotherapy has been performed as the first-line chemotherapy. FOLFOX, which is a chemo- (c) 2014 S. Karger AG, Basel

0012-2823/14/0891-0043\$39.50/0 
Fig. 1. Optimal morphologic response after treatment. a Baseline CT. b The first follow-up CT.
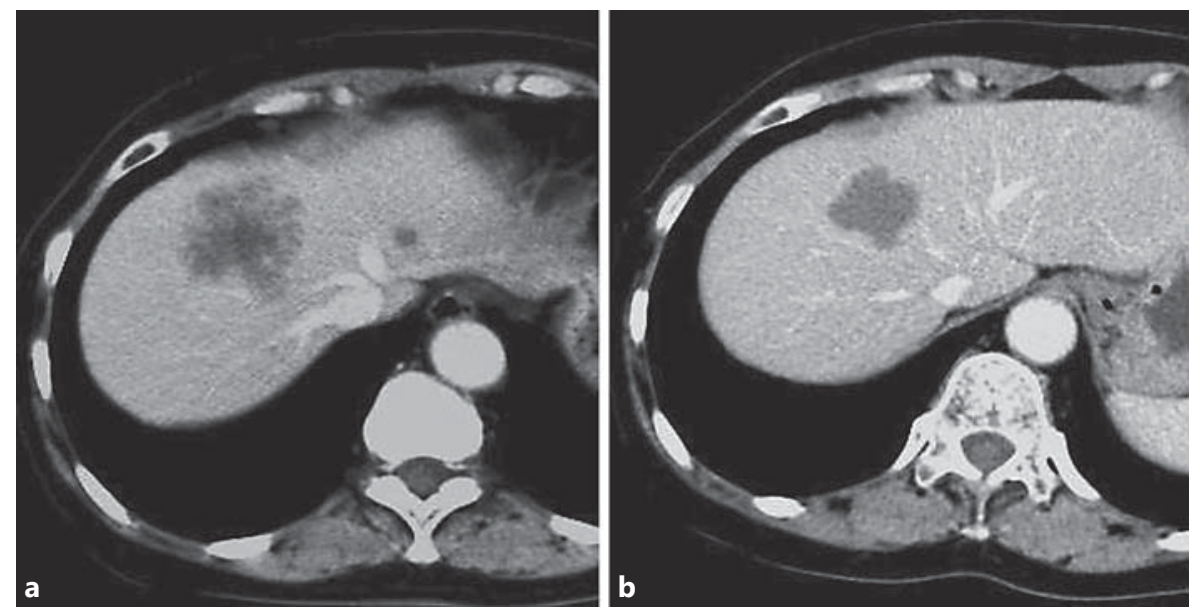

therapy regimen consisting of 5-FU/leucovorin (LV) plus oxaliplatin, prolonged progression-free survival (PFS) compared with 5-FU/LV [1]. 5-FU/LV plus irinotecan (FOLFIRI) also provided a significant clinical benefit [2]. A randomized study comparing FOLFOX with FOLFIRI demonstrated similar efficacy [3]. The combination of capecitabine plus oxaliplatin (XELOX) was found to be noninferior to FOLFOX in terms of PFS in the NO16966 trial [4]. Therefore, FOLFOX, FOLFIRI and XELOX are considered to be the standard chemotherapy regimens in patients with mCRC.

Bevacizumab, a monoclonal antibody against vascular endothelial growth factor, improved the outcome in patients with $\mathrm{mCRC}$ when used in combination with a cytotoxic regimen. In randomized studies, the addition of bevacizumab to oxaliplatin-based chemotherapy (FOLFOX or XELOX) improved PFS [5], and the addition of bevacizumab to irinotecan-based chemotherapy improved not only PFS but also overall survival (OS) [6].

Recently, it was reported that the morphologic criteria observed on computed tomography (CT) were significantly associated with pathologic response and OS in patients with colorectal liver metastases (CLM) undergoing chemotherapy with bevacizumab [7]. Morphologic response to preoperative chemotherapy was also an independent prognostic factor in patients who underwent hepatic resection of CLM [8]. The aim of this study was to evaluate the predictive value of morphologic response to first-line chemotherapy with or without bevacizumab in patients with CLM.

\section{Patients and Methods}

Between April 2006 and June 2012, we assessed patients with CLM who received fluorouracil-based chemotherapy with or without bevacizumab as first-line chemotherapy at 2 institutions. $\mathrm{Pa}$ tients who seemed to be unsuitable for hepatic resection were eligible for this study.

Eligible patients also fulfilled the following criteria: (1) a histologically confirmed diagnosis of adenocarcinoma of the colorectum; (2) treatment with first-line therapy, and (3) no extrahepatic disease except the primary tumor. Patients with a history of previous chemotherapy were excluded from the study.

All patients were considered to be unsuitable for upfront hepatic resection for at least one of the following reasons: more than four metastases; any liver metastasis with diameter $>5 \mathrm{~cm}$; synchronous metastases, and technically difficult to resect, for example, because the metastases involved intrahepatic vascular structures. Among these patients, 41 patients in whom both pre- and postchemotherapy CT images were available were included in this study.

Chemotherapy regimens were selected individually. Treatments were repeated until disease progression, the occurrence of unacceptable toxicity or the patient's refusal to continue therapy.

All patients underwent enhanced CT at the start of chemotherapy and then every 2-3 months. Enhanced CT scans were performed with multislice CT, using a triphasic liver protocol or single-phase technique. Three blinded radiologists evaluated CT images and classified them as optimal, incomplete or no response according to the morphologic criteria [7]. Morphologic response was assessed at the first follow-up CT compared with baseline CT. Group 1 metastasis had homogeneous morphology and hypoattenuation with a thin, sharply defined tumor-normal liver interface. Group 3 metastasis had morphology of heterogeneous attenuation with a thick, poorly defined tumor-normal liver interface. Group 2 metastasis had morphology that did not qualify for either group 1 or 3 .

Optimal response was defined as a change in morphology from group 3 or 2 to group 1 after chemotherapy (fig. 1). Incomplete response was defined as a change in morphology from group 3 to 2. Morphologic response was defined as no response if the metastasis did not change or increased in morphology. In discordant 
cases in response evaluation, the images were reviewed together by radiologists and a consensus resolution was reached. Response to systemic chemotherapy was also evaluated according to Response Evaluation Criteria in Solid Tumors (RECIST) [9]. The patients with complete response or partial response were categorized as responders and the remaining patients with either stable disease or progressive disease were categorized as nonresponders.

\section{Statistical Analysis}

PFS was defined as the period from the date of treatment start to the date of disease progression or death from any cause. Patients undergoing hepatic resection were censored at the time of surgery. PFS was calculated with the Kaplan-Meier method, and the significant differences between survival curves were determined by the log-rank test. The $\chi^{2}$ test and Fisher's exact test were used for frequency comparisons. To identify predictive factors for PFS, univariate and multivariate analyses were performed using Cox proportional hazards model. All statistical analyses were performed with JMP version 10 (SAS Institute, Cary, N.C., USA), and twosided $p$ values $<0.05$ were considered to indicate statistical significance.

\section{Results}

\section{Patients Characteristics}

The patient characteristics are shown in table 1 . The median age was 67 years (range 52-80). Most patients (90\%) had a good performance status (ECOG PS 0-1). Thirty-two patients (78\%) had synchronous liver metastases and 36 (88\%) had multiple liver lesions. All patients received fluorouracil-based chemotherapy as the firstline treatment, including FOLFOX $(\mathrm{n}=34 ; 83 \%)$, XELOX $(\mathrm{n}=4 ; 10 \%), \mathrm{S}-1$ plus oxaliplatin $(\mathrm{n}=1 ; 2 \%)$, FOLFIRI $(\mathrm{n}=1 ; 2 \%)$ and 5 -FU/LV $(\mathrm{n}=1 ; 2 \%)$. Twenty-three patients $(56 \%)$ received chemotherapy plus bevacizumab, while 18 (44\%) received chemotherapy alone.

\section{Efficacy}

Assessment of first-line chemotherapy response using RECIST showed that 3 patients (7\%) were classified with complete response, 18 (44\%) were classified with partial response, $19(46 \%)$ were classified with stable disease and $1(2 \%)$ was classified with progressive disease. The overall response rate and disease control rate were 51 and $98 \%$, respectively. The response rate was comparable between $48 \%$ in the chemotherapy plus bevacizumab group and $56 \%$ in the chemotherapy alone group $(\mathrm{p}=0.62)$.

According to morphologic response criteria, optimal morphologic response was observed in 16 patients (39\%), 13 (32\%) had incomplete response and 12 (29\%) had no response. Optimal morphologic response was observed in $11(48 \%)$ out of 23 patients treated with chemotherapy
Table 1. Baseline characteristics

\section{Patients, $\mathrm{n} \quad \%$}

\begin{tabular}{lll} 
Age, years & & \\
$\quad$ Median & 67 & \\
$\quad$ Range & $52-80$ & \\
Gender & & 71 \\
$\quad$ Male & 29 & 29 \\
$\quad$ Female & 12 & \\
Performance status & & 59 \\
$\quad 0$ & 24 & 32 \\
1 & 13 & 7 \\
2 & 3 & 2 \\
3 & 1 & \\
Primary tumor & & 71 \\
$\quad$ Colon & 29 & 29 \\
$\quad$ Rectum & 12 & 12 \\
Number of metastases & & \\
$\quad$ Solitary & 5 & \\
$\quad$ Multiple & 36 & \\
Occurrence of metastases & & \\
$\quad$ Synchronous & 32 & \\
$\quad$ Metachronous & 9 & \\
Size of metastases, mm & & \\
$\quad$ Median & 39 \\
$\quad$ Range & $10-134$ & \\
Fluorouracil-based chemotherapy regimen & & \\
$\quad$ Chemotherapy with bevacizumab & 23 & 56 \\
$\quad$ Chemotherapy without bevacizumab & 18 & \\
\hline
\end{tabular}

plus bevacizumab and $5(28 \%)$ out of 18 patients treated with chemotherapy alone $(p=0.19)$. Eight patients $(20 \%)$ underwent hepatic resection after chemotherapy. The median follow-up period was 31.3 months. The median PFS by morphologic response was 13.3 months in patients with optimal response and 8.7 months in those with incomplete/no response ( $p=0.0026$; fig. $2 a)$, while the median PFS by RECIST was 11.1 months in responders and 7.1 months in nonresponders $(p=0.021$; fig. $2 b)$.

\section{Predictors for PFS}

Table 2 lists the results of univariate and multivariate analysis of the predictors of PFS. Performance status and morphologic response were significant independent predictors of a favorable outcome ( $\mathrm{p}=0.030$ and 0.0086 , respectively). RECIST was not a significant predictor ( $\mathrm{p}=$ 0.57 ); therefore, morphologic response was superior to RECIST for prediction of PFS. 
Fig. 2. a PFS by morphologic response cri-
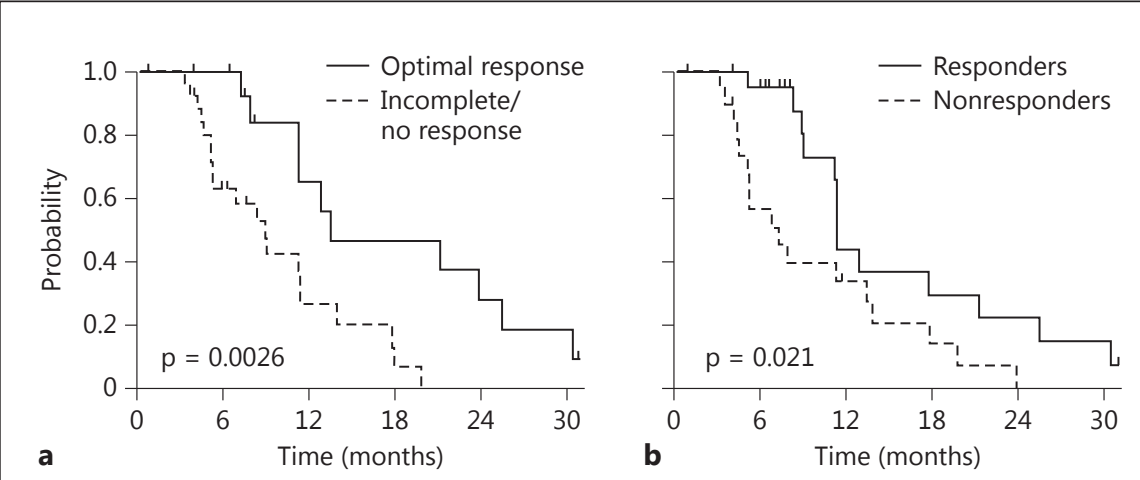
teria. b PFS by RECIST.

Table 2. Univariate and multivariate analysis of PFS

\begin{tabular}{|c|c|c|c|c|c|c|c|}
\hline \multirow[t]{2}{*}{ Factors for criteria } & \multirow[t]{2}{*}{$\mathrm{n}$} & \multicolumn{3}{|c|}{ Univariate analysis } & \multicolumn{3}{|c|}{ Multivariate analysis } \\
\hline & & HR & $95 \% \mathrm{CI}$ & $\mathrm{p}$ & HR & $95 \%$ CI & $\mathrm{p}$ \\
\hline \multicolumn{8}{|l|}{ Age, years } \\
\hline$<65$ & 18 & & & & & & \\
\hline$\geq 65$ & 23 & 2.29 & $1.07-5.19$ & 0.033 & 1.56 & $0.68-3.83$ & 0.30 \\
\hline \multicolumn{8}{|l|}{ Performance status } \\
\hline $0-1$ & 37 & & & & & & \\
\hline$\geq 2$ & 4 & 3.90 & $1.10-11.0$ & 0.037 & 4.41 & $1.18-13.8$ & 0.030 \\
\hline \multicolumn{8}{|c|}{ Occurrence of metastases } \\
\hline Metachronous & 9 & & & & & & \\
\hline Synchronous & 32 & 1.26 & $0.54-3.44$ & 0.61 & & & \\
\hline \multicolumn{8}{|l|}{ Number of metastases } \\
\hline Solitary & 5 & & & & & & \\
\hline Multiple & 36 & 2.37 & $0.49-42.4$ & 0.34 & & & \\
\hline \multicolumn{8}{|l|}{ Size of metastases } \\
\hline$<5 \mathrm{~cm}$ & 26 & & & & & & \\
\hline$\geq 5 \mathrm{~cm}$ & 15 & 1.15 & $0.53-2.37$ & 0.72 & & & \\
\hline \multicolumn{8}{|l|}{ Bevacizumab } \\
\hline Yes & 23 & & & & & & \\
\hline No & 18 & 1.39 & $0.66-2.87$ & 0.38 & & & \\
\hline \multicolumn{8}{|l|}{ RECIST } \\
\hline Responder & 21 & & & & & & \\
\hline Nonresponder & 20 & 2.40 & $1.13-5.31$ & 0.023 & 1.30 & $0.53-3.32$ & 0.57 \\
\hline \multicolumn{8}{|l|}{ Morphologic response } \\
\hline Optimal & 16 & & & & & & \\
\hline Incomplete/none & 25 & 3.83 & $1.60-10.69$ & 0.0021 & 3.56 & $1.36-10.86$ & 0.0086 \\
\hline
\end{tabular}

\section{Discussion}

It is very important to identify a predictor of favorable outcome in patients treated with chemotherapy. RECIST criteria are the current standard in assessing tumor response of solid tumors to cytotoxic agents [9]. However, it is reported that tumor response according RECIST is not predictive of PFS or OS benefit for mCRC treated with chemotherapy with or without bevacizumab [10].

In the present study, we evaluated the predictive value of morphologic response to first-line chemotherapy with or without bevacizumab in patients who seemed to be unsuitable for upfront hepatic resection from colorectal cancer. The median PFS was significantly longer in patients 
with optical morphologic response than those with incomplete/no morphologic response. On multivariate analysis, morphologic response was a significant independent predictor of PFS and was superior to RECIST for prediction of PFS. Therefore, our study indicated that morphologic response to chemotherapy with or without bevacizumab might be useful to predict PFS in patients with CLM.

Although not statistically significant, optimal morphologic response was higher in the patients treated with chemotherapy plus bevacizumab than in the patients treated with chemotherapy alone. A previous study indicated that bevacizumab was strongly associated with an optimal morphologic response in multivariate analysis [8]. Boonsirikamchai et al. [11] concluded that RECIST is insufficient to assess response for chemotherapy with bevacizumab in CLM and the combined use of RECIST and morphologic response criteria is necessary for optimal evaluation. Morphologic response is not difficult to determine except for the small lesions (usually $<1-1.5$ $\mathrm{cm}$ ) [8], and morphologic response criteria can be a useful tool to assess tumor response in patients with CLM in clinical practice.

Several tumor-response evaluation criteria have been developed to assess the response with the introduction of molecular-targeted agents. With anti-EGFR therapy, early tumor shrinkage was an important predictor of favorable outcome in patients with $\mathrm{mCRC}$ who received cetuximab with chemotherapy $[12,13]$. In the case of patients with hepatocellular carcinoma treated with sorafenib, modified RECIST (mRECIST), which takes tumor vascularity into account and was designed specifically for hepatocellular carcinoma, was indicated to be more beneficial for the assessment of treatment efficacy than RECIST criteria $[14,15]$. Furthermore, new CT response criteria evaluating not only tumor size, but also tumor density were proposed to assess the response to imatinib for patients with gastrointestinal stromal tumor and the criteria showed significantly better correlation with time to progression than RECIST [16].

Our study had several important limitations. It was a retrospective study of a small number of patients and selection bias may have potentially affected our results. Our findings should thus be confirmed in prospective clinical trials.

In conclusion, optimal morphologic response was significantly associated with PFS in patients with CLM who were treated with fluorouracil-based chemotherapy as the first-line chemotherapy. Chemotherapy with bevacizumab tends to have a higher optimal morphologic response than chemotherapy without bevacizumab. The results from this study indicate optimal morphologic criteria to be superior to RECIST for prediction of PFS.

\section{Disclosure Statement}

The authors have no conflicts of interest to declare.

\section{References}

1 de Gramont A, Figer A, Seymour M, Homerin $\mathrm{M}$, Hmissi A, Cassidy J, Boni C, CortesFunes H, Cervantes A, Freyer G, Papamichael D, Le Bail N, Louvet C, Hendler D, de Braud F, Wilson C, Morvan F, Bonetti A: Leucovorin and fluorouracil with or without oxaliplatin as first-line treatment in advanced colorectal cancer. J Clin Oncol 2000;16:2938-2947.

$>2$ Douillard JY, Cunningham D, Roth AD, Navarro M, James RD, Karasek P, Jandik P, Iveson T, Carmichael J, Alakl M, Gruia G, Awad L, Rougier P: Irinotecan combined with fluorouracil compared with fluorouracil alone as first-line treatment for metastatic colorectal cancer: a multicentre randomised trial. Lancet 2000;355:1041-1047.

$>3$ Tournigand C, André T, Achille E, Lledo G, Flesh M, Mery-Mignard D, Quinaux E, Couteau C, Buyse M, Ganem G, Landi B, Colin P, Louvet C, de Gramont A: FOLFIRI followed by FOLFOX6 or the reverse sequence in advanced colorectal cancer: a randomized GERCOR study. J Clin Oncol 2004;22:229-237.
4 Cassidy J, Clarke S, Díaz-Rubio E, Scheithauer W, Figer A, Wong R, Koski S, Lichinitser M, Yang TS, Rivera F, Couture F, Sirzén F, Saltz L: Randomized phase III study of capecitabine plus oxaliplatin compared with fluorouracil/folinic acid plus oxaliplatin as first-line therapy for metastatic colorectal cancer. J Clin Oncol 2008;26:2006-2012.

5 Saltz LB, Clarke S, Díaz-Rubio E, Scheithauer W, Figer A, Wong R, Koski S, Lichinitser M, Yang TS, Rivera F, Couture F, Sirzén F, Cassidy J: Bevacizumab in combination with oxaliplatin-based chemotherapy as first-line therapy in metastatic colorectal cancer: a randomized phase III study. J Clin Oncol 2008; 26:2013-2019.

6 Hurwitz H, Fehrenbacher L, Novotny W, Cartwright T, Hainsworth J, Heim W, Berlin J, Baron A, Griffing S, Holmgren E, Ferrara N, Fyfe G, Rogers B, Ross R, Kabbinavar F: Bevacizumab plus irinotecan, fluorouracil, and leucovorin for metastatic colorectal cancer. N Engl J Med 2004;350:2335-2342.
7 Chun YS, Vauthey JN, Boonsirikamchai P, Maru DM, Kopetz S, Palavecino M, Curley SA, Abdalla EK, Kaur H, Charnsangavej C, Loyer EM: Association of computed tomography morphologic criteria with pathologic response and survival in patients treated with bevacizumab for colorectal liver metastases. JAMA 2009;302:2338-2344.

8 Shindoh J, Loyer EM, Kopetz S, Boonsirikamchai P, Maru DM, Chun YS, Zimmitti G, Curley SA, Charnsangavej C, Aloia TA, Vauthey JN: Optimal morphologic response to preoperative chemotherapy: an alternate outcome end point before resection of hepatic colorectal metastases. J Clin Oncol 2012;30:45664572 .

-9 Therasse P, Arbuck SG, Eisenhauer EA, Wanders J, Kaplan RS, Rubinstein L, Verweij J, Van Glabbeke M, van Oosterom AT, Christian MC, Gwyther SG: New guidelines to evaluate the response to treatment in solid tumors. J Natl Cancer Inst 2000;92:205-216.
Predictive Value of Optimal Morphologic Response to Chemotherapy in CLM 
10 Grothey A, Hedrick EE, Mass RD, Sarkar S, Suzuki S, Ramanathan RK, Hurwitz HI, Goldberg RM, Sargent DJ: Response-independent survival benefit in metastatic colorectal cancer: a comparative analysis of N9741 and AVF2107. J Clin Oncol 2008;26:183-189.

11 Boonsirikamchai P, Asran MA, Maru DM, Vauthey JN, Kaur H, Kopetz S, Loyer EM: CT findings of response and recurrence, independent of change in tumor size, in colorectal liver metastasis treated with bevacizumab. AJR Am J Roentgenol 2011;197:W1060W1066.

12 Piessevaux H, Buyse M, De Roock W, Prenen H, Schlichting M, Van Cutsem E, Tejpar S: Radiological tumor size decrease at week 6 is a potent predictor of outcome in chemorefractory metastatic colorectal cancer treated with cetuximab (BOND trial). Ann Oncol 2009;20:1375-1382.
13 Modest DP, Laubender RP, Stintzing S, Giessen C, Schulz C, Haas M, Mansmann U, Heinemann V: Early tumor shrinkage in patients with metastatic colorectal cancer receiving first-line treatment with cetuximab combined with either CAPIRI or CAPOX: an analysis of the German AIO KRK 0104 trial. Acta Oncol 2013;52:956-962.

14 Edeline J, Boucher E, Rolland Y, Vauléon E, Pracht M, Perrin C, Le Roux C, Raoul JL: Comparison of tumor response by Response Evaluation Criteria in Solid Tumors (RECIST) and modified RECIST in patients treated with sorafenib for hepatocellular carcinoma. Cancer 2012;118:147-156.
5 Kawaoka T, Aikata H, Murakami E, Nakahara T, Naeshiro N, Tanaka M, Honda Y, Miyaki D, Nagaoki Y, Takaki S, Hiramatsu A, Waki K, Takahashi S, Chayama K: Evaluation of the mRECIST and $\alpha$-fetoprotein ratio for stratification of the prognosis of advanced-hepatocellular-carcinoma patients treated with sorafenib. Oncology 2012;83:192-200.

16 Choi H, Charnsangavej C, Faria SC, Macapinlac HA, Burgess MA, Patel SR, Chen LL, Podoloff DA, Benjamin RS: Correlation of computed tomography and positron emission tomography in patients with metastatic gastrointestinal stromal tumor treated at a single institution with imatinib mesylate: proposal of new computed tomography response criteria. J Clin Oncol 2007;25:1753-1759. 